\title{
FRCcalc - Software for design of fiber reinforced concrete elements according to MC2010 recommendations
}

Tiago Valente ${ }^{1}$, Joaquim Barros ${ }^{2}$ and Lúcio Lourenço ${ }^{1}$

${ }^{1}$ : CiviTest, Pesquisa de Novos Materiais para a Engenharia Civil, Lda., V. N. de Famalicão, Portugal.

2 : University of Minho, Guimarães, Portugal.

\begin{abstract}
A new software, denominated FRCcalc, was developed for the analysis and design of fiber reinforced concrete (FRC) members based on the recommendations and design guidelines of MC2010. The software is guided for the analysis of FRC cross-sections with and without conventional steel reinforcements, submitted to bending and shear, in order to assess the ultimate and serviceability limit state safety verifications of structural members. A main feature of the software is the possibility to run a comparative analysis between FRC and reinforced concrete (RC) cross-sections from the technical aspects.

Two examples of the analysis of FRC and RC cross-sections using FRCcalc are presented, having been explored the use of fiber reinforcement in members for increased structural performance and as a total or partial replacement of conventional steel reinforcement.

Additionally, in order to appraise FRCcalc accuracy to evaluate the flexural response of FRC and RC cross-sections, a comparison with the results obtained with DOCROS software is presented, being DOCROS based on a layered model capable of attributing to each layer an aimed constitutive model, therefore adequate to predict the moment-curvature of cross sections composed of several types of cement, metallic and polymer materials.
\end{abstract}

\section{Keywords}

FRC design, MC2010, software, flexural, shear, crack width, crack spacing. 


\section{Introduction}

The final version of fib Model Code 2010 (MC2010) [1], published in 2013, covers the design guidelines and recommendations for the dimensioning process of fiber reinforced concrete (FRC) structural members, namely the definition of constitutive laws for FRC and methods for evaluation of flexural and shear resistance of cross-sections and crack control analysis.

The manual application of the design recommendations and guidelines can represent a significative effort in the design of complex structures, as FRC design introduces concepts that can be new for some structural designers. As an example, for the definition of the constitutive laws of the FRC is necessary to determine the structural characteristic length of the FRC member, that is dependent on the reinforcement distribution in the cross-section and on the actions in the FRC member. When analyzing several FRC members in a structure, this methodology can be quite cumbersome.

A software capable of automating the safety verifications of FRC members according to the design recommendations of MC2010 can represent a very useful tool in the design process of structures with this material that can present economic and technical advantages in several applications [2], [3].

\section{Software for design of FRC members}

Based on the MC2010 design recommendations and guidelines, a new software was developed to assist and automate the verifications of FRC members for serviceability (SLS) and ultimate limit state (ULS) conditions. The software, denominated FRCcalc, is guided to the analysis of rectangular cross-sections with or without conventional passive steel reinforcements, submitted to axial, bending and shear forces.

A main feature of the software is the possibility to run a comparative analysis between FRC and reinforced concrete (RC) cross-sections, which was implemented to assess the technical and economic attributes provided using fiber reinforcement as a total or partial replacement of conventional reinforcement.

FRCcalc allows to perform the following analysis: (i) ultimate flexural capacity of FRC and $\mathrm{RC}$ members; (ii) evaluation of the moment $v s$. curvature relationship of FRC and RC members at ULS; (iii) ultimate shear capacity of FRC and RC members; (iv) evaluation of design crack width of FRC and RC members; (v) determination of moment vs. design crack width relationship of FRC and RC members SLS; (vi) evaluation of stress limitation criteria of FRC and RC members at SLS.

For the analysis of the flexural response of FRC and RC cross-sections, in FRCcalc is assumed that the cross-section remains plane after bending, being the shear deformation ignored. The set of equilibrium and compatibility equations of a generic rectangular cross section, composed of FRC with longitudinal conventional reinforcements can be obtained in accordance to Figure 1.

FRCcalc allows the consideration of two types of top and bottom steel conventional reinforcements. Due to the presence of conventional steel reinforcements, the tensile zone of the cross-section is divided in two parts, one with a height equal to the effective tensile depth, 
FRC2018: Fibre Reinforced Concrete: from Design to Structural Applications Joint ACI-fib-RILEM International Workshop

$h_{c, e f}$, and the other corresponding to the depth $y-h_{c, e f}$. For each zone is determined the structural characteristic length, $l_{c s}$, which requires different post-cracking constitutive laws for each zone (due to different ultimate crack opening, $w_{u}$, which has a direct influence on the $l_{c s}$ ). If no conventional tensile reinforcement is applied, the division of the cross-section is discarded, and an unique post-cracking stress-strain relationship for the FRC in the cross-section is considered ( $l_{c s}$ is equal to the depth of the cross section).

Considering the determination of the effective tensile height, $h_{c, e f}$, due to its dependence of the neutral axis position when analyzing the cross-section of beams and slabs (Figure 7.6-4 of MC2010), the value of $h_{c, e f}$ is not constant during the analysis and is updated in each iteration of the analysis.

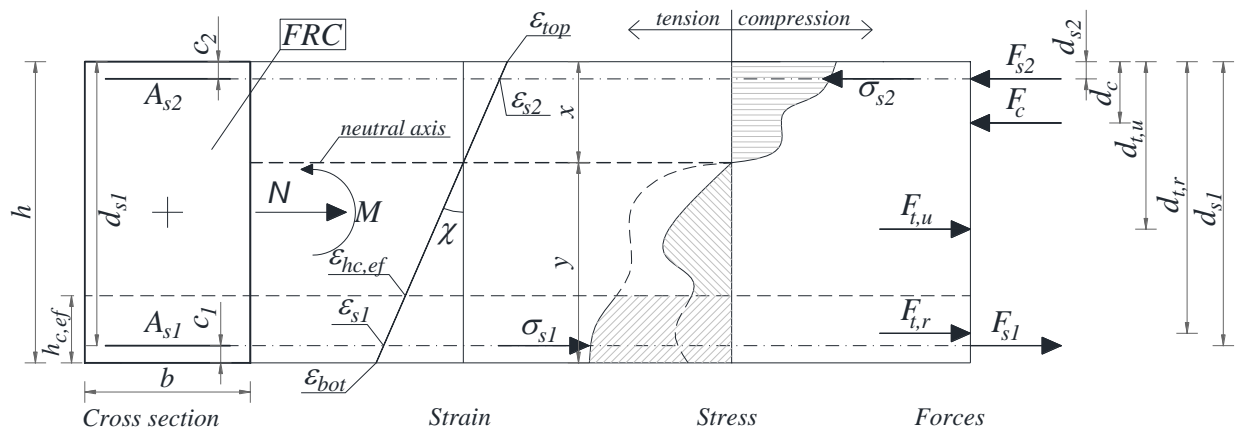

Figure 1-Generic rectangular FRC cross-section for determination of moment-curvature relationship.

In order to simulate the behavior of FRC, plain concrete and conventional steel reinforcements in the cross-section, the constitutive models available in MC2010 are implemented in FRCcalc.

For the compressive behavior of plain concrete and FRC, the bilinear compressive stressstrain law (Figure 7.2-10 of MC2010) is considered.

For the tensile behavior of steel reinforcements, the elastic-perfectly plastic model (Figure 7.2-15 of MC2010) is adopted.

To simulate the tensile behavior of FRC, it is assumed that the pre-peak stage has a similar response to plain concrete (Fig. 5.1-4 of MC2010). For the post-peak stage, the constitutive model to be adopted depends on the limit state verification. For ULS verification it is assumed the linear model (Figure 5.6-7 of MC2010), considering the $l_{c s}$ to convert the concept of crack opening in tensile strain. The complete stress-strain relationship for FRC in tension for ULS analysis is presented in Figure 2.

For the verification of the SLS conditions, one of the three stress-strain models presented in MC2010 (Figure 3) is applicable.

For evaluating the shear resistance of cross-section, the two available models presented in MC2010 are implemented in FRCcalc: the one where fiber reinforcement contribution is empirically considered by using the residual flexural strength (Equation 7.7-5 of MC2010), and 
the model based on the simplified modified compression field theory (SMCFT) (Equation 7.77 of MC2010).

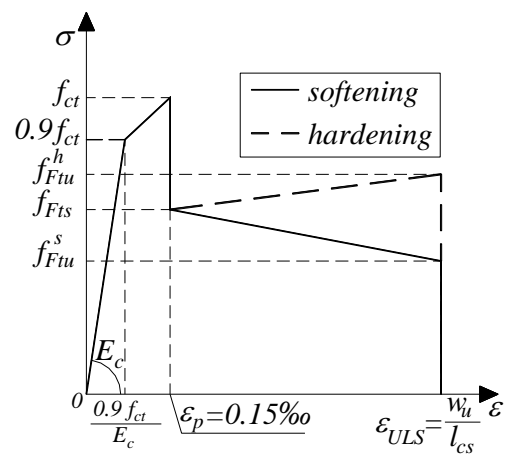

Figure 2-Tensile stress-strain diagram for ULS analysis of FRC.

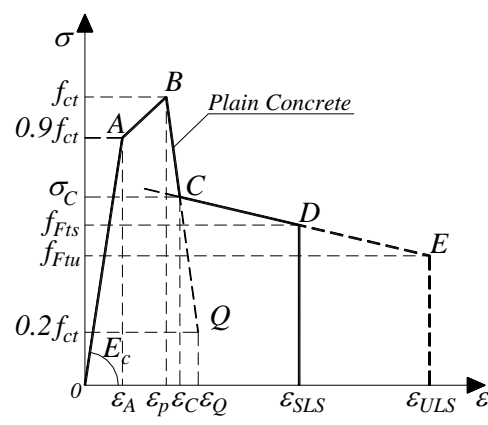

(a)

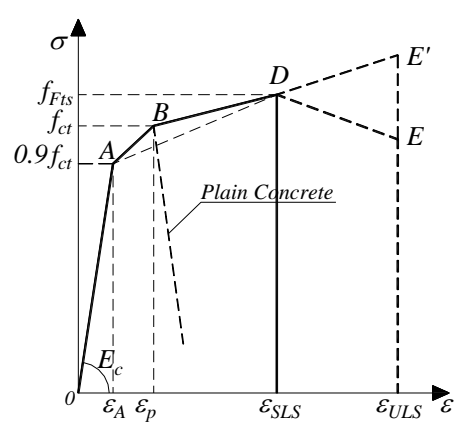

(b)

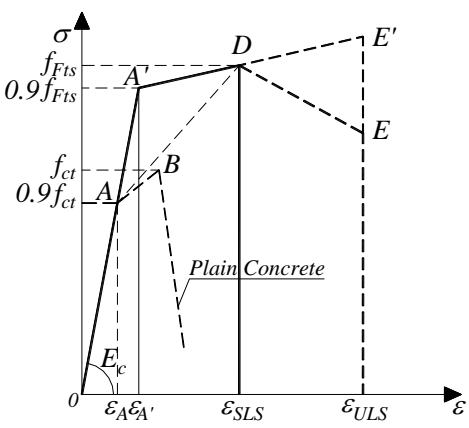

(c)

Figure 3 - Tensile stress-strain diagrams for SLS analysis of FRC: (a) Case I; (b) Case II; (c) Case III.

The application of the SMCFT model resorts to the concept of the direct tensile strength of the FRC. As in MC2010 there is no guidelines to estimate this property based on the toughness and strength classes of FRC, in FRCcalc is adopted the expression proposed by [4] to estimate the characteristic value of the post-cracking tensile stress of FRC, namely:

$$
\begin{gathered}
f_{T k}(w)=k_{G} \min \left(0.4 f_{R 2 k}+1.2\left(f_{R 4 k}-f_{R 2 k}\right) \xi(w), f_{c t k, \min }\right) \\
\xi(w)=\alpha w-0.25
\end{gathered}
$$

Equation (1) is based on the work of [5] that derived the $\sigma-w$ relationship of FRC from inverse analysis on the results of prism bending tests. The factor $k_{G}$ takes into account fiber alignment due to casting bias and wall influences that occur in the prism bending test. In Table 1 is presented the value of $k_{G}$ considering the different prism bending test standards. The value of factor $\alpha$ also depends on the prism bending test configuration and is presented in Table 1 .

Table 1 - Value of $k_{G}$ and $\alpha$ depending on prism bending test standards [4].

\begin{tabular}{|l|c|c|}
\hline Prism bending test standard & $k_{G}$ & $\alpha$ \\
\hline ASTM 1609 [6] & 0.70 & $1 / 3$ \\
\hline EN 14651 [7] & 0.60 & $5 / 12$ \\
\hline RILEM TC 162-TDF [8] & 0.60 & $5 / 12$ \\
\hline UNI 11039 [9] & 0.60 & $43 / 84$ \\
\hline
\end{tabular}


FRC2018: Fibre Reinforced Concrete: from Design to Structural Applications Joint ACI-fib-RILEM International Workshop

For design situation where it is only prescribed the toughness and strength class of the FRC, it is possible to estimate the characteristic values of the residual flexural strength $f_{R 2 k}$ and $f_{R 4 k}$ , based on the following relationships [10], [11]:

$$
f_{R i k}=k_{1}\left(V_{f} \cdot \frac{l_{f}}{d_{f}}\right)^{k_{2}} \quad \ldots i=1, \ldots, 4
$$

where $k_{1}=7.5 ; 6.8 ; 6.0 ; 5.5$ and $k_{2}=0.80 ; 0.75 ; 0.70 ; 0.65$. Considering the value of $f_{R 1 k}$ and $f_{R 3 k}$ defined by the toughness class, it is possible to determine an average value for the factor $V_{f} l_{f} / d_{f}$, which is then considered to estimate $f_{R 2 k}$ and $f_{R 4 k}$ based on Eq. (3).

The SMCFT model implemented in FRCcal was applied in an extended version of a shear tests database [12] and the model exhibited satisfactory agreement with the shear tests results (average test to model prediction ratio was equal to 1.32 , with a coefficient of variation was $24 \%)$.

The contribution to the shear resistance provided by the presence of conventional transverse steel reinforcement in a FRC cross-section is only considered in the SMCFT model, and it is determined following the Level II approximation presented in SMCFT (\$7.3.3.3 of MC2010). For RC cross-sections the shear resistance is determined in compliance with $\S 7.3 .3$ of MC2010, namely the Level II approximation for members with transverse reinforcements.

The crack control assessment of FRC and RC members is determined according to $\$ 7.6 .4$ of MC2010. For FRC members are considered the appropriate modifications provided in \$7.7.4.2 of MC2010, namely the introduction of the influence of the post-cracking resistance of FRC in the introduction length $l_{s, \max }$ and on the steel stress at crack location $\sigma_{s r}$.

Additionally, algorithms are also implemented in FRCcalc for the verification of stress limitation criteria at SLS, according to $\$ 7.6 .3$ and $\$ 7.7 .4 .1$ of MC2010.

FRCcalc was developed in Visual Basic for Application programming language and can be used in Microsoft Office Excel. The resolution of the nonlinear system of equations used in the analysis of the flexural and shear capacity of the cross-section are iteratively solved resorting to the Microsoft Office Excel Solver algorithm [13].

In Figure 4 is presented the user interface window of the software, where the geometry of the cross-section and material properties data are inputted, as well as the type of analysis to be conducted (ULS and/or SLS).

The outputs of FRCcalc are presented in the form of a datasheet and graphs, namely: (i) structural characteristic length of the FRC cross-section; (ii) maximum resisting bending moment of the FRC and RC cross-sections; (iii) ultimate shear resistance of the FRC and RC cross-sections; (iv) plot of the resisting moment vs. curvature of the FRC and RC cross-sections; (v) design crack width and mean crack spacing of the FRC and RC cross-sections; (vi) plot of the moment $v s$. design crack width of the FRC and RC cross-sections; (vii) assessment of stress limitation at SLS for FRC and RC cross-sections. 


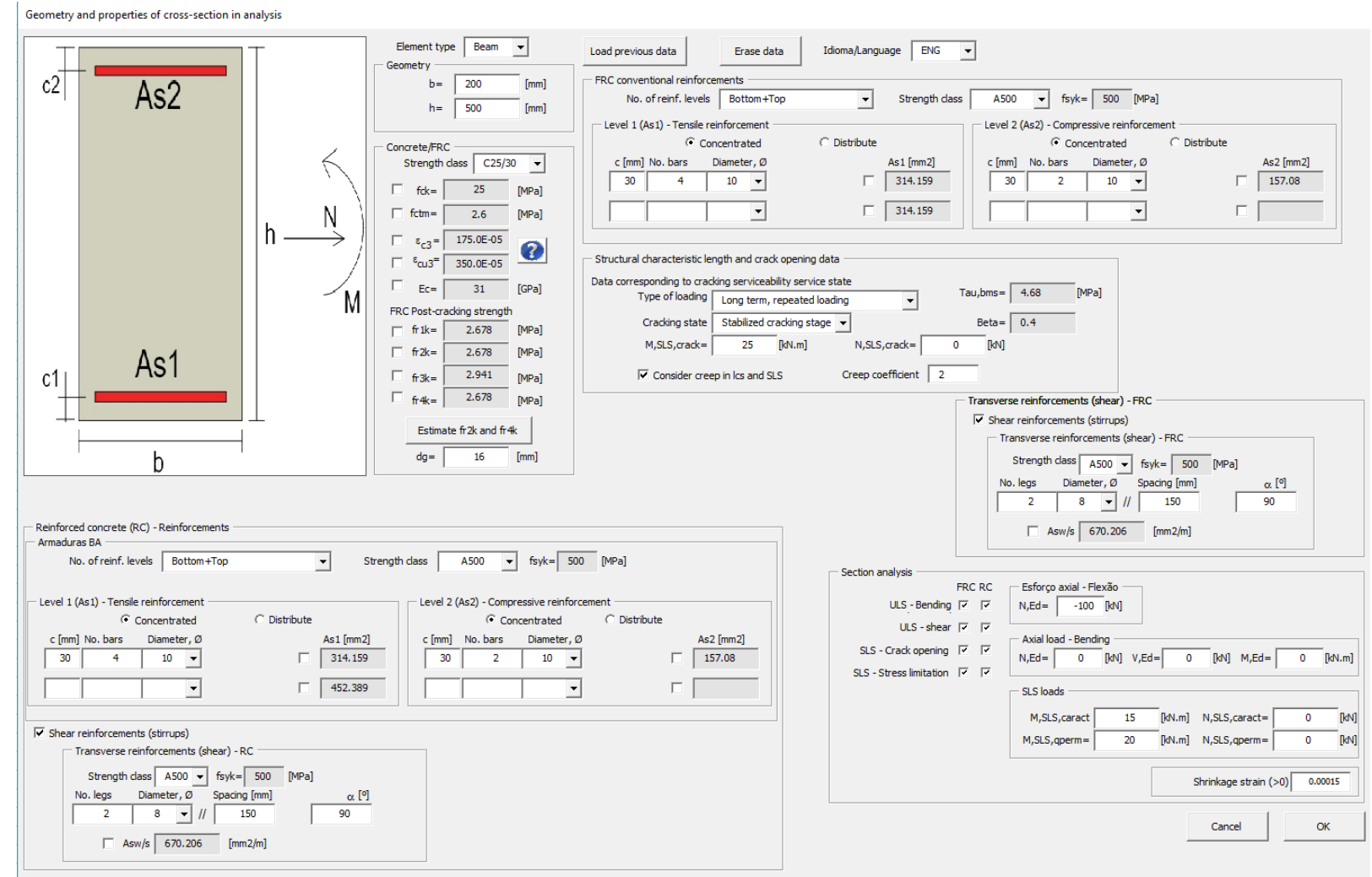

Figure 4-User interface window of the software.

\section{Design examples}

In the first example is analyzed a cross-section of a slab submitted to bending and shear without axial force, being explored the possibility of partial replacement of conventional steel reinforcement by the addition of fibers to concrete. In Figure 5 are presented the main properties of the cross-section.

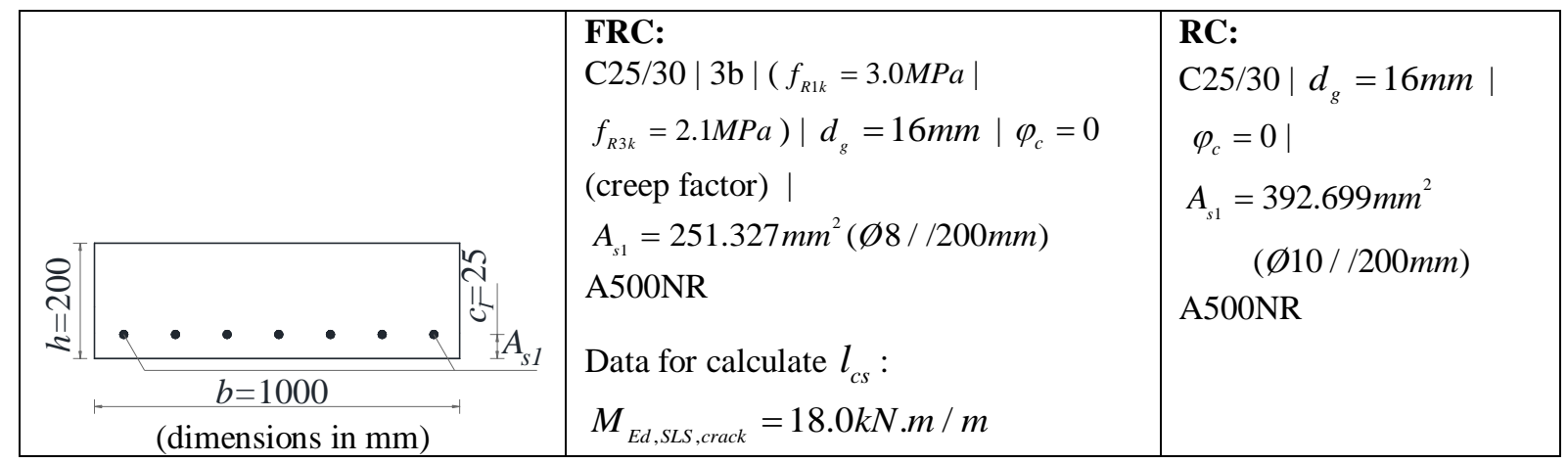

Figure 5 - Cross-section data of example no. 1.

In Figure 6a is presented the moment vs. curvature relationship for a FRC and RC crosssections determined by FRCcalc. The structural characteristic length of the FRC cross-section presents the following values: $l_{c s}^{r}=133.544 \mathrm{~mm}$ and $l_{c s}^{u}=143.917 \mathrm{~mm}$, where $l_{c s}^{r}$ and $l_{c s}^{u}$ is the structural characteristic length in the effective tensile zone and in the remaining part of the cross-section, respectively. 
FRC2018: Fibre Reinforced Concrete: from Design to Structural Applications Joint ACI-fib-RILEM International Workshop

The design shear resistance of the FRC and RC cross-sections are, respectively, $V_{R d}^{F R C}=172.22 \mathrm{kN}$ and $V_{R d}^{R C}=121.54 \mathrm{kN}$, which represents a $42 \%$ increase of the shear strength of the cross-section provided by fiber reinforcement. The presented FRC shear resistance was determined according to the model based on the SMCFT theory, considering that $V_{E d, U L S}=35 \mathrm{kN} / \mathrm{m}, M_{E d, U L S}=10 \mathrm{kN} . \mathrm{m} / \mathrm{m}$, and estimating that $f_{R 2 k}=2.55 \mathrm{MPa}$ and $f_{R 4 k}=2.35 \mathrm{MPa}$.

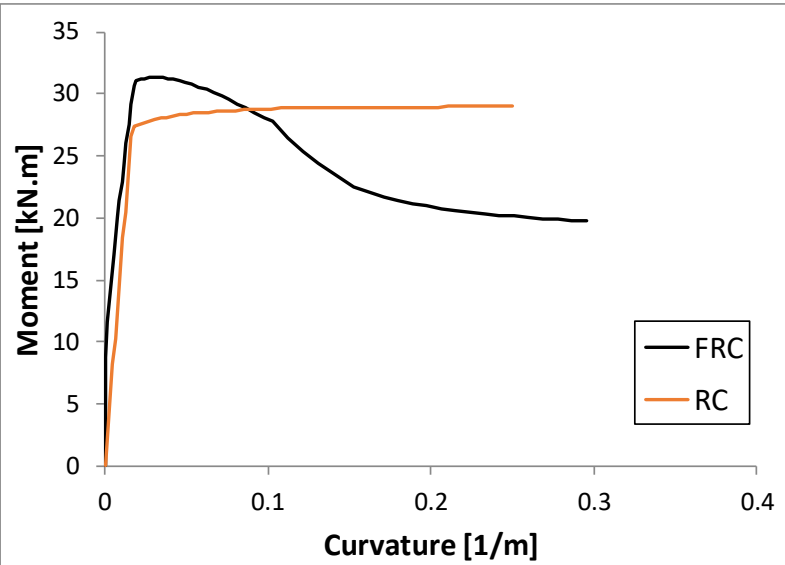

a)

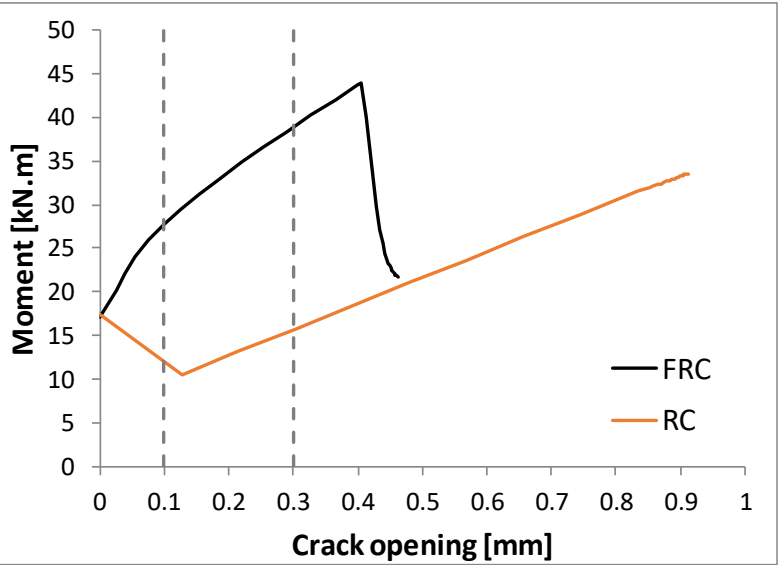

b)

Figure 6 - FRC and RC cross-section results of example no. 1 slab determined by FRCcalc: a) Bending moment vs. curvature relationship at ULS conditions; b) Design crack width vs. resisting bending moment relationship at SLS conditions.

In Figure $6 \mathrm{~b}$ is presented the relationship between the design crack width and the acting moment in the cross-section evaluated at SLS conditions. For a load combination corresponding to cracking serviceability criteria $\left(M_{E d, S L S, \text { crack }}=18.0 \mathrm{kN} . \mathrm{m} / \mathrm{m}\right)$, the FRC cross-section presents a design crack width equal to $w_{d}^{F R C}=0.019 \mathrm{~mm}$ and a mean crack spacing of $s_{r m}^{F R C}=91.271 \mathrm{~mm}$, while the RC cross-section presents a design crack width value of $w_{d}^{R C}=0.378 \mathrm{~mm}$ and a mean crack spacing of $s_{r m}^{R C}=322.721 \mathrm{~mm}$, which corresponds to a 20x reduction of the design crack width. For a crack width corresponding to the minimum and maximum value of crack opening commonly adopted in the SLS verifications, the resisting bending moment of the FRC crosssection is considerably higher than the RC cross-section $(2.3 \mathrm{x}$ higher for $w=0.1 \mathrm{~mm}$ and $2.4 \mathrm{x}$ for $w=0.3 \mathrm{~mm})$.

In Table 2 are presented the stresses in the cross-section for verifying the stress limitation criteria presented in MC2010, considering the acting bending moment for the quasi-permanent load combinations is $M_{E d, S L S, \text { qperm }}=15 \mathrm{kN} . \mathrm{m} / \mathrm{m}$ and for the characteristic load combination is $M_{E d, S L S, \text { char }}=28 \mathrm{kN} . \mathrm{m} / \mathrm{m}$. As can be seen, the use of fiber reinforcements provides a decrease of the stress in the cross-section when compared to the performance of a RC cross-section, especially of the steel bars stress, where for the RC cross-section the limitation criteria for the steel bars tensile stress is not verified according to MC2010 criteria.

The second example corresponds to FRC/RC cross-section of a beam. In Figure 7 are presented the main properties of the cross-section. The main objective of this example is to demonstrate the increase of structural performance provided by the use of fiber reinforcement when compared to a RC cross-section, and to compare the predictive performance of FRCcalc 
with the software DOCROS. DOCROS is a software used in the analysis of cross-sections subjected to axial load and increasing curvature, and it was developed by the Structural Composites research group of the Department of Civil Engineering of University of Minho. In $D O C R O S$ a cross-section is discretized in layers, for which is assigned a specific constitutive law to describe the material behavior. A detailed description of DOCROS can be found in [14], [15].

Table 2 - Verification of stress limitation criteria for Example no. 2 slab.

\begin{tabular}{|c|c|c|c|}
\hline \multicolumn{4}{|c|}{ Concrete compressive stress } \\
\hline Stress & & Limit & Result \\
\hline$\sigma_{c, F R C}^{S L S, \text { char }}=6.83 M P a$ & $\leq$ & $0.6 \cdot f_{c k}(t=28)=15 M P a$ & Verified \\
\hline$\sigma_{c, R C}^{S L S, \text { char }}=8.92 \mathrm{MPa}$ & $\leq$ & $0.6 \cdot f_{c k}(t=28)=15 M P a$ & Verified \\
\hline$\sigma_{c, F R C}^{S L S, q p e r m}=2.70 M P a$ & $\leq$ & $0.4 \cdot f_{c k}(t=28)=10 M P a$ & Verified \\
\hline$\sigma_{c, R C}^{S L S, \text { char }}=5.74 \mathrm{MPa}$ & $\leq$ & $0.4 \cdot f_{c k}(t=28)=10 M P a$ & Verified \\
\hline \multicolumn{4}{|c|}{ Steel tensile stress } \\
\hline Stress & & Limit & Result \\
\hline$\sigma_{s, F R C}^{\text {SLS, char }}=145.56 \mathrm{MPa}$ & $\leq$ & $0.8 \cdot f_{y k}=400 M P a$ & Verified \\
\hline$\sigma_{s, R C}^{\text {SLSchar }}=439.87 \mathrm{MPa}$ & $>$ & $0.8 \cdot f_{y k}=400 M P a$ & Not verified \\
\hline \multicolumn{4}{|c|}{ FRC tensile stress } \\
\hline Stress & & Limit & Result \\
\hline \multicolumn{3}{|c|}{$f_{c t k}$} & Verified \\
\hline
\end{tabular}

\begin{tabular}{|c|c|c|}
\hline \multicolumn{2}{|r|}{0} & $\mathrm{C} 25 / 30 \mid$ FRC: $f_{R l k}=2.678 \mathrm{MPa}\left|f_{R 2 k}=2.508 \mathrm{MPa}\right| f_{R 3 k}=2.941 \mathrm{MPa} \mid$ \\
\hline & If & $f_{R 4 k}=2.950 \mathrm{MPa}$ (Toughness class $\left.2.5 \mathrm{c}\right)\left|d_{g}=16 \mathrm{~mm}\right| \varphi_{c}=0$ \\
\hline 8 & $A_{s w}$ & $A_{s 1}=314.16 \mathrm{~mm}^{2}(4 \varnothing 10) \mathrm{A} 500 \mathrm{NR} \mid A_{s 2}=157.08 \mathrm{~mm}^{2}(2 \varnothing 10) \mathrm{A} 500 \mathrm{NR}$ \\
\hline II & & $A_{s w} / s=502.66 \mathrm{~mm}^{2} / m(\varnothing 8 / / 200 \mathrm{~mm})$ A500NR \\
\hline & $\ldots \pi^{\infty}$ & Data for calculate $l_{c s}$ : \\
\hline & $\begin{array}{l}b=200 \\
\text { mensions in } \mathrm{mm} \text { ) }\end{array}$ & $M_{E d, c r a c k}=40.0 \mathrm{kN} . \mathrm{m}$ \\
\hline
\end{tabular}

Figure 7 -Cross-section data of example no. 2.

In Figure 8a is presented the moment $v s$. curvature relationship for the FRC and RC crosssections determined by FRCcalc and DOCROS. It is possible to observe that the accuracy of FRCcalc to describe the flexural response of the cross-sections is similar to DOCROS.

The structural characteristic length of the FRC cross-section presents the following values: $l_{c s}^{r}=78.61 \mathrm{~mm}$ and $l_{c s}^{u}=425 \mathrm{~mm}$. The maximum resisting bending moment of the FRC cross-section is $M_{R d, U L S}^{F R C}=75.22 \mathrm{kN} . \mathrm{m}$ and of the RC cross-section is $M_{R d, U L S}^{R C}=61.53 \mathrm{kN} . \mathrm{m}$. As can be seen, the postcracking residual strength of the FRC provided a flexural capacity improvement of the beam in $22 \%$ when compared to the RC cross-section.

In Figure $8 \mathrm{~b}$ is presented the relationship between the design crack width and the acting moment in the cross-section evaluated at SLS conditions. For the load combination corresponding to cracking serviceability criteria, the design crack width in the FRC and RC 
FRC2018: Fibre Reinforced Concrete: from Design to Structural Applications Joint ACI-fib-RILEM International Workshop

cross-section are, respectively, $w_{d}^{F R C}=0.074 \mathrm{~mm}$ and $w_{d}^{R C}=0.258 \mathrm{~mm}$, which represent a decrease of crack opening of 3.48x provided by the fiber reinforcements. In addition, the mean crack spacing of the FRC and RC beams are, respectively, $s_{r m}^{F R C}=78.607 \mathrm{~mm}$ and $s_{r m}^{R C}=144.472 \mathrm{~mm}$. For a crack opening of $w=0.1 \mathrm{~mm}$ the flexural capacity of the FRC cross-section is $2.4 \mathrm{x}$ higher than the RC cross-section.

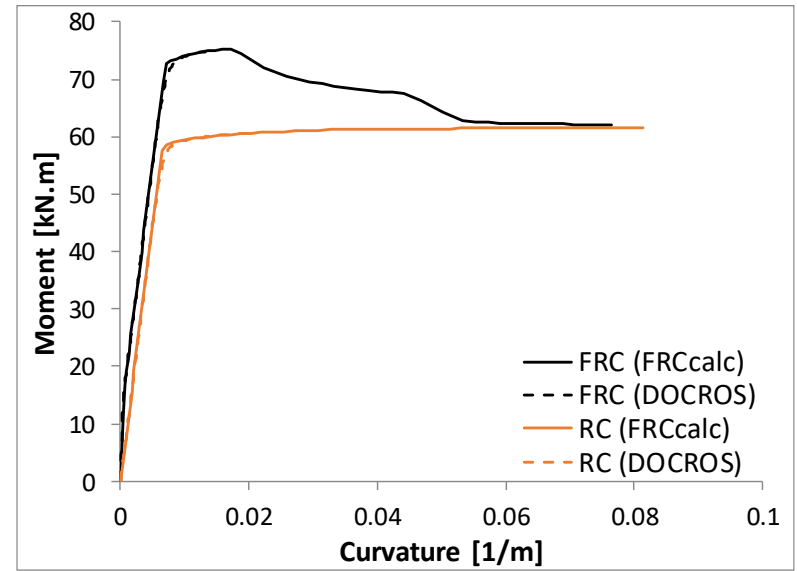

a)

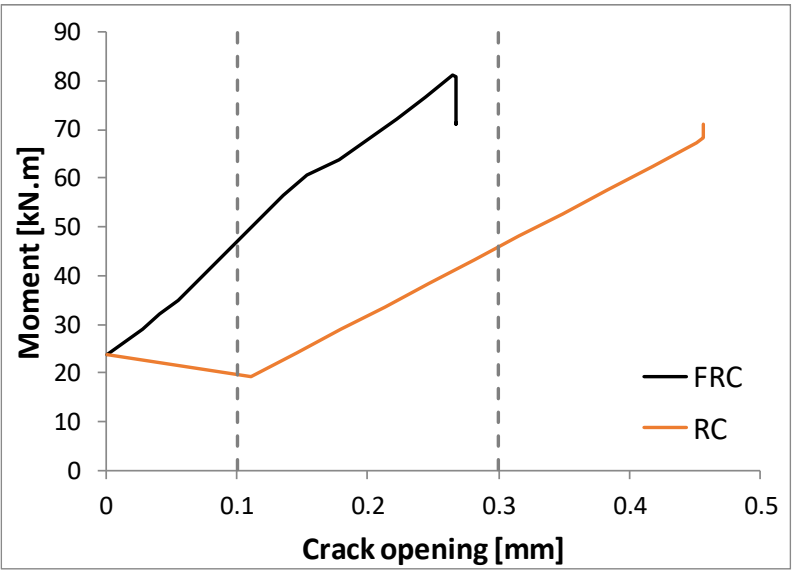

b)

Figure 8-FRC and RC cross-section results of example no.2 beam: a) Bending moment vs. curvature relationship determined by FRCcalc and DOCROS at ULS conditions; b) Design crack width vs. resisting bending moment relationship determined by FRCcalc at SLS conditions.

\section{Conclusions}

In the present work a newly developed software for the analysis of the FRC cross-sections according to MC2010 design guidelines and recommendation is presented. A brief description of the models and principles for analyzing the flexural, shear and cracking response of FRC members are presented, including some design aspects not covered in MC2010 that were included in the software code.

The main features of the software are described, including the ability to perform comparative analysis between FRC and RC cross-sections.

Two examples regarding the use of FRC in structural elements are presented, exploring the increased structural performance provided by the use of fiber reinforcements and the possibility of partial replacement of conventional steel reinforcements. Additionally, the accuracy of FRCcalc to describe the flexural response of FRC and RC cross-section was confirmed by comparison with the software DOCROS.

Future developments of FRCcalc will address the consideration of the prestressed steel bars in the FRC/RC members and the development of a methodology to study the economic advantages on the use of fiber reinforcement as a replacement of conventional steel bars.

\section{Acknowledgements}

The first Author would like to acknowledge the grant SFRH/BDE/96381/2013 co-funded by 
CiviTest - Pesquisa de Novos Materiais para a Engenharia Civil, Lda. and by FCT - Portuguese Foundation for Science and Technology. The authors also acknowledge the support provided by the FCT project PTDC/ECM-EST/2635/2014.

\section{References}

[1] fib-federation internationale du beton, fib Model Code for Concrete Structures 2010. John Wiley \& Sons, 2013.

[2] Ronald F. Zollo, "Fiber-reinforced concrete: an overview after 30 years of development," Cem. Concr. Compos., vol. 19, no. 2, pp. 107-122, 1997.

[3] A. M. Brandt, "Fibre reinforced cement-based (FRC) composites after over 40 years of development in building and civil engineering," Compos. Struct., vol. 86, no. 1-3, pp. 39, Nov. 2008.

[4] S. J. Foster, A. Agarwal, and A. Amin, "Design of steel fiber reinforced concrete beams for shear using inverse analysis for determination of residual tensile strength: FOSTER ET AL.," Struct. Concr., Sep. 2017.

[5] A. Amin, S. J. Foster, and A. Muttoni, "Derivation of the $\sigma-w$ relationship for SFRC from prism bending tests," Struct. Concr., vol. 16, no. 1, pp. 93-105, Mar. 2015.

[6] ASTM International, Standard Test Method for Flexural Performance of FiberReinforced Concrete (Using Beam With Third-Point Loading), vol. ASTM C1609. 2012.

[7] European Committee for Standardization, Test method for metallic fibered concrete Measuring the flexural tensile strength (limit of proportionality (LOP), residual), vol. EN 14651. 2005.

[8] RILEM TC 162-TDF, "Recommendations of RILEM TC 162-TDF: Test and design methods for steel fibre reinforced concrete: bending test," Mater. Struct., vol. 35, no. 253, pp. 579-582, 2002.

[9] Italian Board for Standardization, Steel Fiber Reinforced Concrete-Part I: Definitions, Classification Specification and Conformity-Part II: Test Method for Measuring First Crack Strength and Ductility Indexes, vol. UNI 11039. 2003.

[10] "Punching behaviour of flat slabs of steel fibre reinforced concrete submitted to symmetric loading," PhD thesis, Universidade de Brasília, Brasília, Brasil, 2013.

[11] B. N. Moraes Neto, J. A. O. Barros, and G. S. S. A. Melo, "A model for the prediction of the punching resistance of steel fibre reinforced concrete slabs centrically loaded," Constr. Build. Mater., vol. 46, pp. 211-223, Sep. 2013.

[12] S. J. Foster and A. Argarwal, "Database for testing shear models for SFRC beams and one-way slabs without stirrups," School of Civil and Environmental Engineering, UNSW Sydney, Sydney, Australia, 2017.

[13] Microsoft Office Excel. Microsoft.

[14] C. A. A. Basto and J. A. O. Barros, "Numeric simulation of sections submitted to bending," Department of Civil Engineering, School of Engineering, University of Minho Guimarães,, Portugal, Technical Report 08-DEC/E-46, 2008.

[15] Varma, Rajendra Kumar, "Numerical models for the simulation of the cyclic behaviour of RC structures incorporating new advanced materials," PhD Thesis, Universidade do Minho, 2013. 